\title{
LEADING CHANGES IN ASSESSMENT USING AN EVIDENCE BASED APPROACH
}

\author{
Macaulay, J.O. ${ }^{1}$, Speed, C.J'., Dimitropoulos, A $^{1}$., Simpson,C.M ${ }^{1}$. \\ ${ }^{1}$ Department of Biochemistry and Molecular Biology, Monash University, Victoria, \\ Australia
}

\section{Introduction and objectives}

It is has been widely accepted that assessment of learning is a critical component of education and that assessment drives/guides student learning through shaping study habits and student approaches to learning. However, although most academics would agree that assessment is a critical aspect of their roles as teachers it is often an aspect of teaching that is regarded more as an additional task rather than an integral component of the teaching/learning continuum. An additional impediment to high quality assessment is the non-evidence basedapproach to the decision making process. The overall aim of this project was to improve the quality of assessment in Biochemistry and Molecular Biology undergraduate education by promoting high quality assessment.

\section{Materials and methods}

To do this we developed and trialled an audit tool for mapping assessment practices. The audit tool was designed to gather data on current assessment practices and identify areas of good practice in which assessment aligned with the learning objectives and areas in need of improvement. This evidence base will then be used to drive change in assessment.

\section{Results and conclusions}

Using the assessment mapping tool we have mapped the assessment regime in a Biochemistry and Molecular Biology major at Monash University. Criteria used included: assessment type, format, timing, assessors, provision of feedback, level of learning (Bloom's), approaches taken to planning assessment. We have mapped assessment of content and the systematic development of higher order learning and skills progression throughout the program of study. The data has enabled us to examine the assessment at unit (course) level as well as the vertical development across the major. This information is now being used to inform a review of the units and the major.

Acknowledgements

This project was supported by a Monash University, Faculty of Medicine, Nursing and Health Science Teaching and Learning grant 